\title{
Multidrug Resistant Infections in Paediatric AML: An Ominous Sign of the Times to Come
}

\author{
Suvir Singh ${ }^{1, \odot ~ K u n a l ~ J a i n ~}{ }^{2}$ Jagdeep Singh ${ }^{2}$ Davinder Paul ${ }^{2}$
}

Address for correspondence Suvir Singh, MD, DM, Department of Clinical Hematology \& Bone Marrow Transplantation, Dayanand Medical College and Hospital, Ludhiana, Punjab, 141001, India (e-mail: suvirs@gmail.com).

Ind J Med Paediatr Oncol 2021;42:213-214.

Uppuluri et al recently reported a single center experience with management of pediatric acute myeloid leukemia (AML) and impact of infectious complications over a two-decade period. ${ }^{1}$ This is a highly informative study and allows inference of chronological trends in etiology of infectious complications and mortality in pediatric AML across India. It is commendable to note that despite an increase in the prevalence of multidrug resistant (MDR) organisms, early infection-related mortality of less than $10 \%$ was achieved. We highlight three other pertinent conclusions that must be drawn from this study and have wider implications.

The finding of Klebsiella pneumoniae as the most common Gram-negative pathogen is in line with several other Indian studies on AML. ${ }^{2}$ Alarmingly, the incidence of MDR bacteremia in Indian data continues to increase, with one study noting carbapenem resistance in $60 \%$ and colistin resistance in $80 \%$ of isolates. ${ }^{3}$ An increasing trend in MDR Gram-negative infections after 2012 is echoed in the same study, rising from $0 \%$ before 2012 to over $20 \%$ in 2017 . This has shown exponential rise in the use of colistin, tigecycline, and carbapenems. Despite a rise in MDR infections, the new antibiotic pipeline (including agents in all phases of development) as of 2019 has been found to be similar to the one in 2013 and 2015, indicating an unavoidable lag between emergence of resistant isolates and identification of newer agents. ${ }^{4}$

This trend is foreseen to cause greater challenges in the coming few years, and must be mitigated with steps taken today. First, implementation of antibiotic stewardship programs has been shown to reduce broad-spectrum antibiotic usage in the absence of clinical or microbiologic indications and must be implemented where possible. For instance, pharmacy guidelines that prevent the use of carbapenems without definite indications potentially reduce unnecessary antibiotic usage. The use of stool surveillance, as used by the authors, allows risk-adapted initiation of carbapenems/colistin/tigecycline in appropriate patients and has reduced unnecessary antibiotic usage. Neutropenic patients with AML usually need to be started on broad-spectrum antibiotics agents in the absence of microbiologic proof. Active antibiotic deescalation in AML, guided by microbiology reports, allows a reduction in broad-spectrum antibiotic usage without affecting clinical outcomes and must be followed wherever possible. ${ }^{5}$

Fungal infections constitute the next biggest threat to patients with acute leukemia. Posaconazole provides effective antimold activity and is the agent of choice for most patients with AML. The authors report low rates of proven fungal infections, with the use of micafungin for all patients. Micafungin has demonstrated reduced rates of prophylaxis failure in patients with AML, but it is associated with a similar incidence of invasive fungal infections and a higher incidence of infections with uncommon species like Mucoralres. ${ }^{6}$ Several problems associated with posaconazole such as drug interactions, variable absorption, and peak drug levels are overcome with micafungin, and a decision to switch must be taken based on individual data.

It is again impressive to note that the induction mortality despite high rates of MDR infections has largely stayed around the $10 \%$ mark. Cognizant use of broad-spectrum antibiotics, directed by clinical and microbiologic indications, is essential to prevent the emergence of an MDR Gram-negative pandemic in the coming years.

\section{Author Contributions}

SS and KJ conceptualized the paper. SS wrote the article. SS, KJ, JS, and DP contributed to literature search and reviewed the final manuscript.

The manuscript has been read and approved by all the authors. The requirements for authorship, as stated earlier
DOI https://doi.org/ $10.1055 / \mathrm{s}-0041-1731842$ ISSN 0971-5851
(C) 2021. Indian Society of Medical and Paediatric Oncology. This is an open access article published by Thieme under the terms of the Creative Commons Attribution-NonDerivative-NonCommercial-License, permitting copying and reproduction so long as the original work is given appropriate credit. Contents may not be used for commercial purposes, or adapted, remixed, transformed or built upon. (https://creativecommons.org/licenses/by-nc-nd/4.0/). Thieme Medical and Scientific Publishers Private Ltd. A-12, Second Floor, Sector -2, NOIDA -201301, India 
in this document, have been met, and each author believes that the manuscript represents honest work.

\section{Conflict of Interest}

None declared.

\section{References}

1 Uppuluri R, Swaminathan V, Ravichandran N, et al. Chemotherapy for childhood acute myeloid leukemia and associated infections over two decades in India: Timeline and impact on outcome. Indian J Med Paediatr Oncol 2020;41(6):869-873

2 Jain $H$, Rengaraj $K$, Sharma $V$, et al. Infection prevalence in adolescents and adults with acute myeloid leukemia treated in an Indian tertiary care center. JCO Glob Oncol 2020;6(6):1684-1695

3 Kumar H, Mehra N, Ganesan P, et al. Patterns of infection and mortality associated with intensive AML induction therapy: 10 year experience from a tertiary cancer centre in India. Blood 2018;132(Supplement 1):4008

4 Butler MS, Paterson DL. Antibiotics in the clinical pipeline in October 2019. J Antibiot (Tokyo) 2020;73(6):329-364

5 Fuller R, Moshier E, Jacobs SE, et al. Practicing antimicrobial stewardship: de-escalating antibiotics in patients with acute myeloid leukemia and neutropenic fever. Open Forum Infect Dis 2020;7(5):a138

6 Epstein DJ, Seo SK, Huang Y-T, et al. Micafungin versus posaconazole prophylaxis in acute leukemia or myelodysplastic syndrome: a randomized study. J Infect 2018;77(3):227-234 